\title{
КЛИНИЧЕСКОЕ ТЕЧЕНИЕ ХРОНИЧЕСКОЙ СЕРДЕЧНОЙ НЕДОСТАТОЧНОСТИ С СОХРАНЕННОЙ И ПРОМЕЖУТОЧНОЙ ФРАКЦИЕЙ ВЫБРОСА ЛЕВОГО ЖЕЛУДОЧКА
}

\author{
๑Ф. Ш. Кадырова, М. Э. Рахимова \\ Ташкентская медицинская академия, Узбекистан
}

РЕЗЮМЕ. Целью исследования стало изучение клинических признаков хронической сердечной недостаточности у пациентов с сохраненной (СНсФВ) и промежуточной (СНпФВ) фракцией выброса левого желудочка.

Материал и методы. В исследование были включены 129 пациентов с ХСН. Средний возраст больных составил $(69,2 \pm 11)$ лет, мужчин было 63,2 \%. ХСН развивалась на фоне гипертонической болезни в $88 \%$ случаев, ИБС - в 76 \% случаев, кардиомиопатии - в 9 \% случаев. Больные были поделены на три группы в зависимости от уровня ФВ ЛЖ: 1 группу составили 36 больных с низкой ФВ ЛЖ (СНнФВ), 2 группу - 33 пациента с промежуточной ФВ ЛЖ (СНпФВ), 3 группу - 60 больных с сохранной ФВ ЛЖ (СНсФВ).

Результаты. Результаты исследования показали, что количество пациентов старше 60 лет составило 91,4 \%, 74,3 \%, 62,1 \% соответственно по группам. Гипертоническая болезнь отмечалась у 78 \%, 85,6 \%, 92,6 \% соответственно. Метаболический синдром был выявлен в 1 группе у $18 \%$, во 2 группе -у 31 \%, в 3 группе -у 38 \% больных. Наличие сахарного диабета II типа наблюдалось у 22,8 \%, 32,7 \%, 41,4 \%; постинфарктный кардиосклероз отмечался у 82,3\%, 70,6 \%, 21,4 \% соответственно по группам. Частота сердечных сокращений более 90 ударов в 1 мин. при госпитализации наблюдалась у 41,4 \%, 33,6 \%, 17,5 \%. Фибрилляция предсердий регистрировалась у 39,3 \%, 40,9 \%, 24,8 \% соответственно по группам, гипертрофия левого желудочка по ЭКГ в 93,7 \%, 96,2 \%, 80,2 \% случаях соответственно. Дилатация ЛЖ по эхокардиографии отмечалась в 88,4 \%, 60,9%, 8,2% случаях соответственно распределенным группам.

Выводы. Результаты исследования показали, что в группе больных с ХСНпФВ преобладали лица более молодого возраста и мужского пола. Данная группа отличалась от других групп тем, что у этих больных показатели были ближе к группе пациентов СНнФВ и отличалась от группы с СНсФВ: у них реже встречалась гипертоническая болезнь, чаще - постинфарктный кардиосклероз, тахикардия при поступлении, дилатация левого желудочка и фибрилляция предсердий.

КЛЮчЕВЫЕ СЛОВА: хроническая сердечная недостаточность; фракция выброса.

Вступление. Хроническая сердечная недостаточность (ХCH) признана значимой социальноэкономической проблемой современной медицины в виду непрерывного роста ее распространенности, частых повторных госпитализаций и высокого уровня смертности $[1,4,5]$.

Сердечная недостаточность (CH) - синдром, обусловленный снижением функции сердца, которая приводит к дисбалансу между его возможностями и гемодинамической потребностью организма $[2,6,7]$.

По эпидемиологическим данным, уровень заболеваемости и смертности среди больных ХСН на сегодняшний день остается достаточно высоким. В 2016 году в Узбекистане количество больных с впервые диагностированными заболеваниями сердечно-сосудистой системы достигло 532 015, заболеваемость на 100000 населения составила 22255 человек. По официальным данным в 2016 году в нашей Республике смертность от заболеваний сердечно-сосудистой системы составляла 89734 человек, что составляет 61,6\% от всех смертельных случаев (институт здоровья и медицинской статистики, 2016) за этот год. Проведенные реформы и улучшение жилищно-бытовых условий населения в период независимости привело к удлинению средней продолжительности жизни от 67 до 73 лет. Но это явилось причиной увеличения количества больных хронической систолической и диастолической сердечной недостаточностью [4].

На данный период одинаковый подход к лечению и тактике ведения всех пациентов с ХCH показал свою несостоятельность. Как видно, популяция больных с ХСН неоднородна, поэтому для более точного успеха снижения количества смертности и госпитализации требуется индивидуальный подход к каждому пациенту [3, 4].

Одним из ключевых индикаторов тяжести дисфункции миокарда у пациентов с ХСН является величина глобальной фракции выброса левого желудочка (ФВ ЛЖ), характеризующая его сократительную способность [3].

С 2016 года выделяют 3 формы: СН с низкой (ФВ ЛЖ <40 \%) - СНнФВ, промежуточной (ФВ лж В пределах 40-49 \%) - СНпФВ, и сохранённой (ФВ лж >50 \%) - СНсФВ. ФВ является одним из ключевых показателей гемодинамики при СН и имеет большое прогностическое значение: чем меньше ФВ, тем хуже прогноз. За последнее время в нескольких крупных клинических исследованиях наблюдались больные СНсФВ и не имевшие иной патологии со стороны сердца, например, клапанных нарушений или заболеваний перикарда. 
Огляди літератури, оригінальні дослідження, погляд на проблему, випадок з практики, короткі повідомлення

Больные СНпФВ определяются, как имеющие «промежуточную» ФВ ЛЖ и, по всей видимости, их следует отнести к категории пациентов с незначительной систолической дисфункцией. Как известно, в патогенезе ХСН играют роль как традиционные кардиальные факторы, так и чрезмерная активация нейрогуморальных систем, которая может приводить к гиперторофии миокарда, ремоделированию миокарда и сосудов, развитию гибернации миокарда, систолической и диастолической дисфункции левого желудочка $[7,8]$. В литературе имеются данные об изменении при ХСН концентрации норадреналина, адреналина, ангиотензина II (A-II), натрийуретических пептидов, вазопрессина, эндотелиальных факторов релаксации (NO, эндотелиального фактора гиперполяризации, простациклина, брадикинина) и констрикции (эндотелины 1, 2, 3; эндопероксидтромбоксан-А2; супероксид-анион); опухолевого некротизирующего фактора и т. д. При СНнФВ 2/3 ЕЭС причиной является ИБС, часто в сочетании с АГ и СД. Комбинация ИБС и АГ встречается у $50 \%$ больных, другие причины - предшествующие вирусные инфекции, злоупотребление алкоголем, химиотерапия (доксорубицин или транстузумап) и ДКМП. Пороки сердца, миокардиты относятся к более редким причинам. Главная причина СНсФВ - АГ и заболевания, снижающие податливость миокарда в желудочках (болезни накопления, ИБС, возрастной фиброз, ожирение). Такие пациенты чаще встречаются среди женщин с ожирением, чаще выявляется АГ и ФП, реже ИБС. Причины СНпФВ в настоящее время не детализированы, но предполагается, что это преимущественно те же состояния, что и при СНнФВ $[4,5]$. В связи с распространённостью, ХСН в современном мире достигла масштабов эпидемии, причем ХСН с сохраненной и промежуточной фракциями выброса (СНспФВ) левого желудочка (ЛЖ) встречается по меньшей мере в 50 \% всех случаев $[6,8]$.

Цель - оценить клиническое значение особенности течения хронической сердечной недостаточности (XCH) у пациентов с сохраненной
(ХCH-сФВ) и промежуточной (ХСН-пФВ) фракцией выброса левого желудочка.

Материал и методы. В исследование были включены 129 пациентов с ХСН. Средний возраст больных составил $(69,2 \pm 11)$ лет, мужчин было $63,2 \%$ ХСН развивалась на фоне гипертонической болезни в 88 \% случаев, ИБС - в 76 \% случаев, кардиомиопатии - в 9 \% случаев. Больные были поделены на три группы в зависимости от уровня ФВ ЛЖ: 1 группу составили 36 больных с низкой ФВ ЛЖ - СНнФВ, 2 группу - 33 пациента с промежуточной ФВ ЛЖ - СНпФВ, 3 группу - 60 больных сохранной ФВ ЛЖ - СНсФВ.

Результаты и их обсуждение. Результаты исследования показали, что пациенты старше 60 лет составляли 91,4 \%, 74,3 \%, 62,1 \% соответственно по группам. Гипертоническая болезнь отмечалась у 78 \%, 85,6 \%, 92,6 \% соответственно. Метаболический синдром в 1 группе был выявлен у 18 \%, во 2 группе - у 31 \%, в 3 группе - у 38 \% больных. Наличие сахарного диабета II типа наблюдалось у 22,8 \%, 32,7 \%, 41,4 \%; постинфарктный кардиосклероз отмечался у 82,3 \%, 70,6 \%, $21,4 \%$ соответственно по группам. Частота сердечных сокращений более 90 ударов в 1 мин при госпитализации наблюдалась у 41,4 \%, 33,6 \%, 17,5 \%. Фибрилляция предсердий регистрировалась у 39,3 \%, 40,9 \%, 24,8 \% соответственно по группам, гипертрофия левого желудочка по ЭКГв 93,7 \%, 96,2 \%, 80,2 \% случаев соответственно. Дилатация Лж по эхокардиографии отмечалась В $88,4 \%, 60,9 \%, 8,2$ \% случаев соответственно распределенным группам.

Заключение. Как показали результаты исследования, в группе больных с ХСНпФВ преобладали лица более молодого возраста и мужского пола. Данная группа отличалась от других тем, что у этих больных показатели были ближе к группе пациентов СНнФВ и отличалась от группы с СНсФВ: у них реже встречалась гипертоническая болезнь, чаще определялись постинфарктный кардиосклероз, тахикардия при поступлении, дилатация левого желудочка и фибрилляция предсердий.

\section{ЛИТЕРАТУРА}

1. Хроническая сердечная недостаточность / ред. Ф. Т. Агеев, Г. П. Арутюнов, Ю. Н. Беленков. - М.: Гэотар Медиа, 2010. - Гл. 1- С. 7-77.

2. Напалков Д. А. Хроническая сердечная недостаточность: смещение фокуса на начальные стадии заболевания / Д. А. Напалков, В. А. Сулимов, Н. М. Сеидов // Лечащий врач. - 2008. - № 4. - С. 58-60.

3. Сотникова М. Ю. Кардиология 2-е издание / М. Ю. Сотникова ; под ред. Е. В. Шляхто. - М.: Гэотар Медиа, 2019. - Глава 24. - С. 691.
4. Аляви А.Л. Диагностика и лечение хронической сердечной недостаточности / А. Л. Аляви, У. К. Камилова, 3. Д. Расулова. - Ташкент, 2016. - 196 с.

5. Ташкенбаева Э. Н. Особенности течения нестабильной стенокардии у больных хронической сердечной недостаточностью со сниженной фракцией выброса // Э. Н. Ташкенбаева, Ф.О.Хасанжанова, К. З. Абдуллаев // Наука и современное общество: взаимодействие и развитие. - 2018. - Т. 2, №. 1. - С. 34-36.

6. Связь тяжести хронической сердечной недоста- 
Огляди літератури, оригінальні дослідження, погляд на проблему, випадок з практики, короткі повідомлення точности от локализации острого инфаркта миокарда / Э. Н. Ташкенбаева, Ф.О. Хасанжанова, Д. Д. Хайдарова [и др.] // Наука и современное общество: взаимодействие и развитие. - 2018. - Т. 2, №. 1. - С. 36-38.

7. Применение методов коррекции эндотелиальной дисфункции и пуринового обмена у больных с ишемической болезнью сердца / Э. Н. Ташкенбаева,

Д. Х. Тогаев, Ф. Ш. Кадырова [и др.] // Вестник экстренной медицины. - 2013. - № 3. - С. 238-239.

8. Ташкенбаева Э. Н. Влияние лозартана и небиволола на функцию эндотелия и уровень мочевой кислоты у больных с ишемической болезнью сердца и бессимптомной гиперурекемией / Э. Н. Ташкенбаева, Тогаев Д. Х. // Вісник проблем біології і медицини. - 2012. Вип. 4, Т. 2 (97). - С. 118-122.

\section{REFERENCES}

1. Ageev, F.T., Arutiunuv, G.P., \& Belenkov, Yu.N. (Eds.). (2010). Khronicheskaya serdechnaya nedostatochnost [Chronic heart failure]. Moscow: GEOTAR-Media [in Russian].

2. Napalkov, D.A., Sulimov, V.A., \& Seydov, N.M. (2008). Khronicheskaya serdechnaya nedostatochnost: smeshcheniye fokusa na nachalnyye stadii zabolevaniya [Chronic heart failure: focus at the early stages of the disease]. Lechashchiy vrach - Attending Physician, (4), 58-60 [in Russian].

3. Shliakhto, E.V., \& Sotnikova, M.Yu. (Eds.). (2019). Kardiologiya [Cardiology]. Moscow: GEOTAR-Media [in Russian].

4. Aliavi, A.L., Kamilova, U.K., \& Rasulova, Z.D. (2016). Diagnostika i lecheniye khronicheskoy serdechnoy nedostatochnosti [Diagnosis and treatment of chronic heart failure]. Tashkent [in Russian].

5. Tashkenbaeva, E.N., Hasazhanova, F.O., \& Abdullaev, K.Z. (2018). Osobennosti techeniya nestabilnoy stenokardii u bolnykh khronicheskoy serdechnoy nedostatochnostyu so snizhennoy fraktsiyey vybrosa [Specific features of unstable angina pectoris in patients with congestive heart failure with low ejection fraction]. Nauka i sovremennoye obshchestvo: vzaimodeystviye i razvitiye - Science and Modern Society: Interaction and Development, 2 (1), 34-36 [in Russian].

6. Tashkenbaeva, E.N., Hasazhanova, F.O., Haidarova, D.D., Togaeva, B.M., \& Nasirova, Z.A. (2018). Svyaz tyazhesti khronicheskoy serdechnoy nedostatochnosti ot lokalizatsii ostrogo infarkta miokarda [Correlation between the heart failure's severity and localization of acute myocardial infarction]. Nauka i sovremennoye obshchestvo: vzaimodeystviye i razvitiye - Science and Modern Society: Interaction and Development, 2 (1), 36-38 [in Russian].

7. Tashkenbaeva, E.N., Togaev, D.G., Kadirova, F.Sh., Yusupov, Sh.Sh., Muranov, B.A. (2013). Primeneniye metodov korrektsii endotelialnoy disfunktsii i purinovogo obmena u bolnykh $\mathrm{s}$ ishemicheskoy boleznyu serdtsa [Methods of correction of endothelial dysfunction and purine metabolism in patients with ischemic heart disease]. Vestnik ekstrennoy meditsiny - Herald of Emergency Medicine, (3), 238-239 [in Russian].

8. Tashkenbaeva, E.N., \& Togaev, D.G. (2012). Vliyaniye lozartana i nebivolola na funktsiyu endoteliya i uroven mochevoy kisloty u bolnykh s ishemicheskoy boleznyu serdtsa i bessimptomnoy giperurekemiyey [Losartan and nebivolol impact on the endothelial function and level of urea acid in patients with ischemic heart disease and non-symptomatic hyperuricemia]. Visnyk problem biolohii $i$ medytsyny - Bulletin of Problems of Biology and Medicine, 2 (97), 118-122 [in Russian].

\section{КЛІНІЧНИЙ ПЕРЕБІГ ХРОНІЧНОЇ СЕРЦЕВОЇ НЕДОСТАТНОСТІ ІЗ ЗБЕРЕЖЕНОЮ ТА ПРОМІЖНОЮ ФРАКЦІЕЮ ВИКИДУ ЛІВОГО ШЛУНОЧКА}

๑Ф. Ш. Кадирова, М. Є. Рахімова

\section{Ташкентська медична академія, узбекистан}

РЕзЮМЕ. Метою дослідження стало вивчення клінічних ознак хронічної серцевої недостатності у пацієнтів із збереженою (СНзФВ) і проміжною (СНпФВ) фракцією викиду лівого шлуночка.

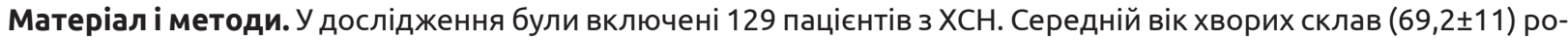
ків, чоловіків було 63,2 \%. ХСН розвивалася на тлі гіпертонічної хвороби у 88 \% випадків, IXC - у 76 \% випадків, кардіоміопатії - в 9\% випадків. Хворі були поділені на три групи залежно від рівня ФВ ЛШ: 1 групу склали 36 хворих з низькою ФВ ЛШ (СНнФВ), 2 групу - 33 пацієнта з проміжною ФВ ЛШ (СНпФВ), 3 групу - 60 хворих зі збереженою ФВ ЛШ (СНзФВ).

Результати. Результати дослідження показали, що кількість пацієнтів старше 60 років склала 91,4 \%, 74,3 \%, 62,1 \% відповідно по групах. Гіпертонічна хвороба відзначалася у 78 \%, 85,6 \%, 92,6 \% відповідно. Метаболічний синдром був виявлений в 1 групі у $18 \%$, у 2 групі - у 31 \%, в 3 групі - у 38 \% хворих. Наявність цукрового діабету II типу спостерігалася у 22,8 \%, 32,7 \%, 41,4 \%; постінфарктний кардіосклероз відзначався у 82,3 \%, 70,6 \%, 21,4 \% відповідно по групах. Частота серцевих скорочень більше 90 ударів за 1 хв при госпіталізації спостерігалася у 41,4 \%, 33,6 \%, 17,5 \%. Фібриляція передсердь реєструвалася у 39,3 \%, 40,9 \%, 24,8 \% відповідно по групах, гіпертрофія лівого шлуночка за ЕКГ в 93,7 \%, 96,2 \%, 80,2 \% випадках відповідно. Дилатація ЛШ на ехокардіографії відзначалася в 88,4 \%, 60,9%, 8,2 \% випадків відповідно до розподілених груп. 
Огляди літератури, оригінальні дослідження, погляд на проблему, випадок з практики, короткі повідомлення

Висновки. Результати дослідження показали, що в групі хворих з ХСНпФВ переважали особи більш молодого віку і чоловічої статі. Ця група відрізнялася від інших тим, що у цих хворих показники були ближчими до групи пацієнтів СНпФВ і відрізнялася від групи з СНзФВ: у них рідше зустрічалася гіпертонічна хвороба, частіше - постінфарктний кардіосклероз, тахікардія при надходженні, дилатація лівого шлуночка і фібриляція передсердь.

КлючОВІ СлОВА: хронічна серцева недостатність; фракція викиду.

\title{
THE CLINICAL COURSE OF CHRONIC HEART FAILURE WITH PRESERVED AND INTERMEDIATE LEFT VENTRICULAR EJECTION FRACTION
}

\author{
@F. Sh. Kadyrova, M. E. Rakhimova
}

Tashkent Medical Academy, Tashkent, Uzbekistan

SUMMARY. The aim of the study was to evaluate the clinical features of chronic heart failure (CHF) course in patients with preserved (CHF-pEF) and intermediate (CHF-intEF) left ventricle ejection fraction (LVEF).

Material and Methods. The study included 129 patients with CHF. The average age was (69.2 \pm 11$)$ years, men $63.2 \%$. CHF developed on the background of hypertension in $88 \%$, CHD - in $76 \%$, cardiomyopathy - in $9 \%$ of cases. Patients were divided into three groups: group 1 comprised 36 patients with low LVEF - CHF-pEF, group 2 - 33 patients with intermediate LVEF - CHF-pEF, and group 3 of 60 patients with preserved LVEF - CHF-intEF.

Results. Patients older than 60 years were $91.4 \%, 74.3 \%, 62.1 \%$, respectively, in the groups. Hypertension was observed in $78 \%, 85.6 \%, 92.6 \%$, respectively. Metabolic syndrome was detected in group 1 in $18 \%$, in group 2 - in $31 \%$, in group 3 - in $38 \%$ of patients. The presence of type II diabetes was observed in $22.8 \%, 32.7 \%, 41.4 \%$; postinfarction cardiosclerosis was observed in $82.3 \%, 70.6 \%, 21.4 \%$, respectively, in the groups. A heart rate of more than 90 beats per 1 min during hospitalization was observed in $41.4 \%, 33.6 \%, 17.5 \%$. Atrial fibrillation was recorded in $39.3 \%$, $40.9 \%$, $24.8 \%$, respectively, in groups, left ventricular hypertrophy by ECG in $93.7 \%, 96.2 \%, 80.2 \%$ of cases, respectively. LV dilatation by echocardiography was observed in $88.4 \%, 60.9 \%, 8.2 \%$ of cases, respectively, in groups.

Conclusions. The group with CHFpEF predominated with people of a younger age and male in the study. This group differed from other groups in that in these patients the indicators were closer to the group of patients with CHF-pEF and differed from the group with CHF-intEF: they were less likely to have hypertension, more often postinfarction cardiosclerosis, tachycardia upon admission, dilatation of the left ventricle and atrial fibrillation.

KEY WORDS: chronic heart failure; ejection fraction. 